UCRL-JC-123329

$$
\text { CONF- } 960493-20
$$

\title{
Applied Grinding Wheel Performance Evaluation for Optical Fabrication*
}

\section{Mark A. Piscotty, John S. Taylor, Kenneth L. Blaedel}

Lawrence Livermore National Laboratory

This paper was prepared for submittal to

Optical Society of America

Optical Fabrication and Testing Topical Meeting

Boston, MA

May 1-3, 1996

AECENED

SEP 061996

OSTI

June 11, 1996




DISCLAIMER

This document was prepared as an account of work sponsored by an agency of the United States Government. Neither the United States Government nor the University of California nor any of their employees, makes any warranty, express or implied, or assumes any legal liability or responsibility for the accuracy, completeness, or usefulness of any information, apparatus, product, or process disclosed, or represents that its use would not infringe privately owned rights. Reference herein to any specific commercial product, process, or service by trade name, trademark, manufacturer, or otherwise, does not necessarily constitute or imply its endorsement, recommendation, or favoring by the United States Government or the University of California. The views and opinions of authors expressed herein do not necessarily state or reflect those of the United States Government or the University of California, and shall not be used for advertising or product endorsement purposes. 


\section{DISCLAIMER}

Portions of this document may be illegible in electronic image products. Images are produced from the best available original document. 
Applied Grinding Wheel Performance Evaluation for Optical Fabrication

\author{
Mark A. Piscotty, John S. Taylor, Kenneth L. Blaedel \\ Lawrence Livermore National Laboratory \\ L-537, P.O. Box 808 \\ Livermore, CA 94551 \\ $510-422-2052$ fax: $510-423-1460$
}

We are collaborating with the Center for Optics Manufacturing (Rochester, NY) to develop optimal designs of fine diamond grinding wheels for the spherical grinding of glass optics. To this end, we typically employ a standardized method for wheel performance evaluation that focuses on workpiece quality, including surface roughness, figure and subsurface damage. New elements of our work include the use of in-process acoustic emission (AE) measurements for correlating with performance and the use of 3-D surface profiles of wheel topography. This paper includes recent AE measurements taken during the evaluation of several fine diamond grinding wheels and discusses how this new information might relate to the physical performance of the wheels. An interesting observation is also reported relating to the surface topography of wom bronze wheels using an interferometric profiler.

Our standardized methodology for performance evaluation of grinding wheels includes in-process monitoring and experimental grindability measurements. Each wheel evaluation begins by truing and dressing the wheel using standardized methods. Process monitoring includes grinding ratio and force measurements and the recently installed acoustic emission sensing technique. Although the use of $\mathrm{AE}$ as a research tool is not $n e w^{2}{ }^{3}$,we find that it may provide valuable information for assessing wheel performance. Figures 1 (a) and (b) show AE signal traces during the grinding process using resin and bronze bond, fine $(2 / 4 \mu \mathrm{m})$ diamond wheels (all of which used identical speeds, in-feed rates, depths of cut and dwell periods). In figure 1(a), the three bronze wheels demonstrate different $\mathrm{AE}$ profiles during grinding, probably due to varying wheel characteristics (bond hardness, porosity, diamond distribution, etc.). Once the dwell period is reached, however, the AE signals for all three wheels ramp down to approximately the same magnitude. We hypothesize that the decline of the signals marks the end of material removal and the grits are elastically rubbing against the workpiece surface. In contrast, figure 1(b) presents the AE grinding signals of two resin bond wheels. Unlike their bronze bond counterparts, the AE signals for these wheels do not drop off during the dwell period, implying that material removal is still occuring. We attribute this behavior to the higher compliance of the resin bonds relative to the bronze bond wheels. We anticipate correlating real-time AE signals with grinding wheel performance and workpiece quality in the near future. Future force measurements will enable interesting correlations between wheel activity and induced deflections.

A long term goal may be to use in-process AE sensing as a tool for the continuous sensing of grinding quality which may reduce the need for labor-intensive off-line part measurements for process control. This work is part of an on-going evaluation of diamond grinding wheels relevant to the optics industry.

\footnotetext{
- This work was performed under the auspices of the U.S. Dept of Energy by LLNL under contract No. W-7405-Eng-48.
} 
A new adjunct to our wheel evaluation is the examination of wheel topography using a 3-D white light interferometric surface profiler (Zygo New View). Shown in Figure 2, we used this profiler to examine the topography of a typical set of three bronze bond grinding wheels $(220$ grit, $10 / 20 \mu \mathrm{m}, 2 / 4 \mu \mathrm{m})$. Figure 2(a) presents the surface topography of the 220 grit wheel where two large diamonds are visibly protruding from the bond. The surface of the $10 / 20 \mu \mathrm{m}$ wheel is shown in figure 2(b) in which the grooved structure indicates the direction of grinding. Several diamond are seen protruding 2-6 $\mu \mathrm{m}$ above the binder. Lastly, the $2 / 4 \mu \mathrm{m}$ wheel topography in figure 2(c) demonstrates the dominant feature to be 5-7 $\mu \mathrm{m}$ hillocks of the bond matrix with slight or no protruding diamond grits. This is an interesting observation because the bond undulations are clearly larger than the heights of any diamonds protruding from the surface. This may have important implications regarding the role of the bond in wheel-to-workpiece interactions such as rubbing. It is our hope to utilize this imaging tool to better understand the interaction between the grinding wheel and the workpiece.

${ }^{1}$ M.A. Piscotty, J.S. Taylor, K.L. Blacdel, Pefformance Evaluation of Bound Diamond Ring Tools, SPIE San Diego, CA, SPIE 2536-28 (July 1995).

${ }^{2}$ Dornfeld, D and Blum, T, Grinding Process Feedback Using Acoustic Emission, SME, MR90-525, October 1990.

${ }^{3}$ Inasaki, I., Monitoring of Dressing and Grinding Processes with Acoustic Emission Signals, Annals of CIRP, Vol. 34/1, 1995.

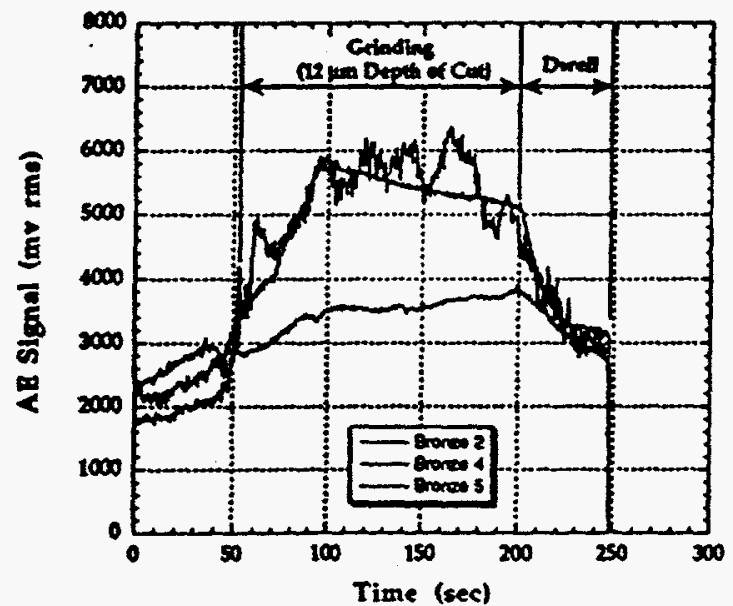

1 (a)

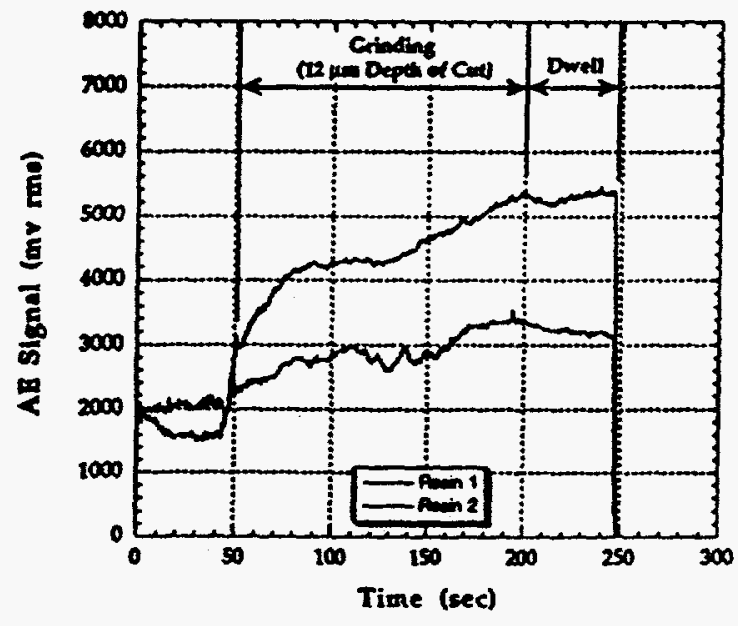

1 (b)

Figure 1 (a) and (b) - In-process monitoring of acoustic emission during grinding indicates significant differences between bronze and resin bond wheels, particularly during the dwell periods. 


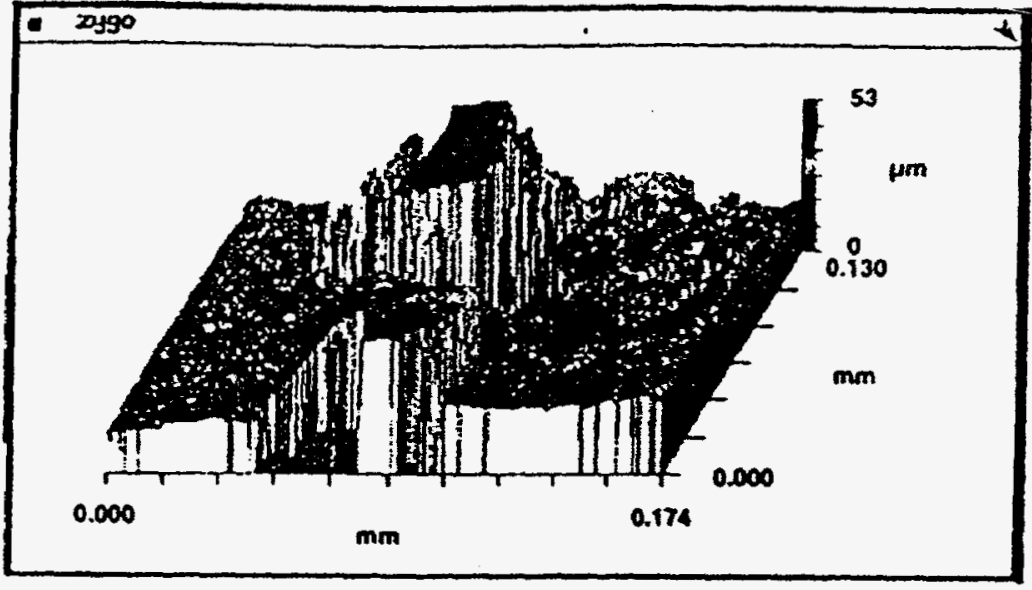

2 (a)

10-20 micron - bronze wheel

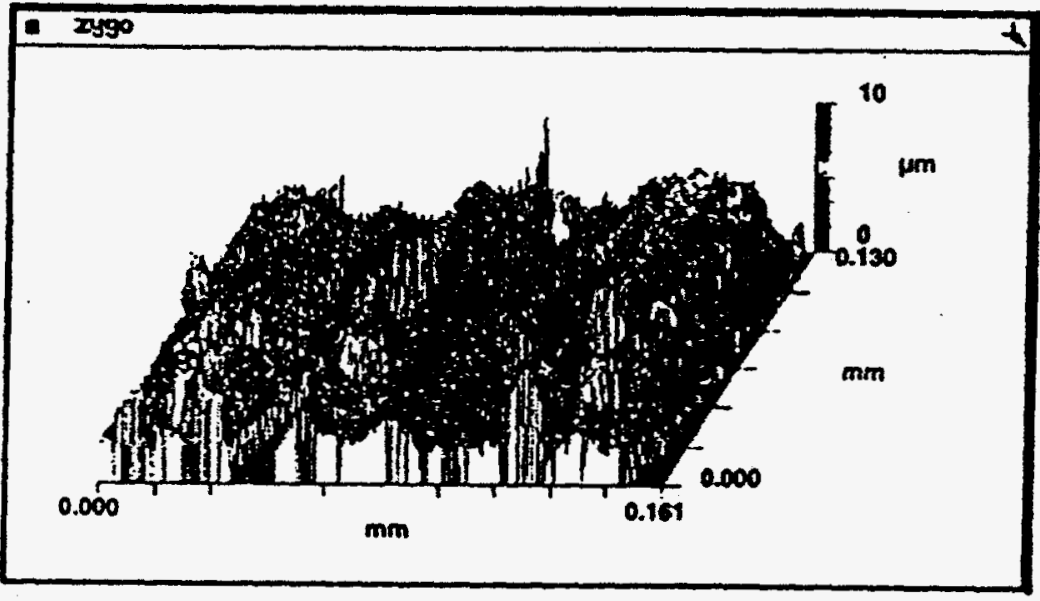

2 (b)

2-4 micron - bronze wheel

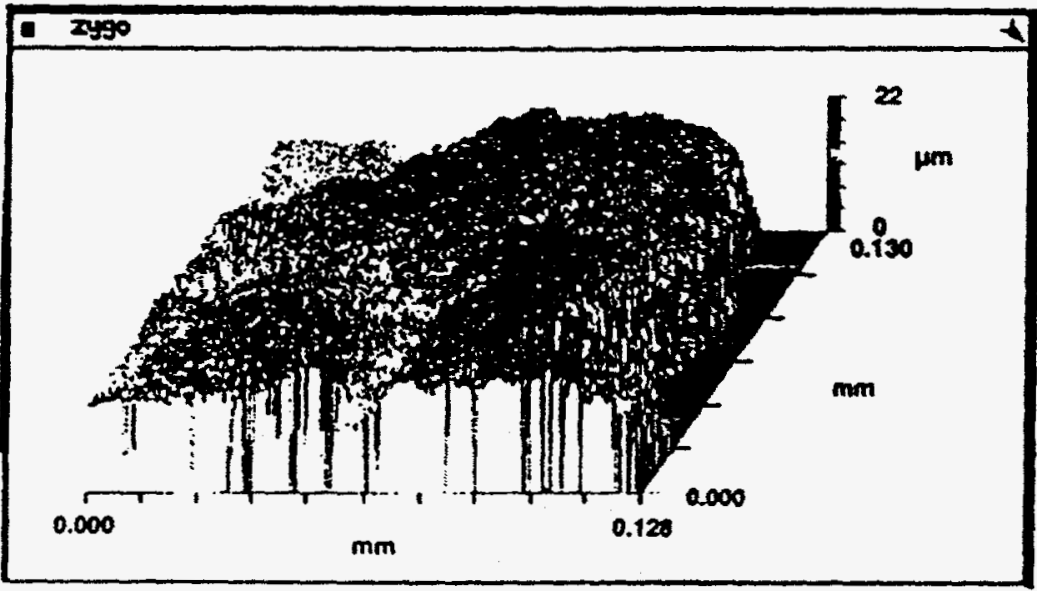

2 (c)

Figure 2 (a) - (c) - Surface topography of three diamond bronze bond grinding wheels with different grit sizes as measured with a Zygo New View (courtesy of Mark Palvino, Zygo Corp.). 
96050369

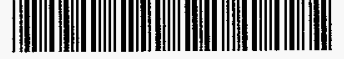




$$
\begin{gathered}
\text { UCRL-JC-123003 } \\
\text { PRERINT } \\
1196050369 \\
\text { CONF-960425--11 }
\end{gathered}
$$

\title{
Magnetic Force Microscopy of Single-Domain Cobalt Dots Patterned Using Interference Lithography
}

\author{
A. Fernandez, P. J. Bedrossian, S. L. Baker, S. P. Vernon, D. R. Kania
}

This paper was prepared for submittal to the International Magnetics Conference

Seattle, WA

April 9-12, 1996
RECEIVED

SEP $0^{9} 1996$

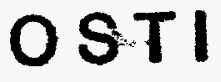

March 20, 1996 


\section{DISCLAIMER}

This document was prepared as an account of work sponsored by an agency of the United States Government. Neither the United States Government nor the University of California nor any of their employees, makes any warranty, express or implied, or assumes any legal liability or responsibility for the accuracy, completeness, or usefulness of any information, apparatus, product, or process disclosed, or represents that its use would not infringe privately owned rights. Reference herein to any specific commercial product, process, or service by trade name, trademark, manufacturer, or otherwise, does not necessarily constitute or imply its endorsement, recommendation, or favoring by the United States Government or the University of California. The views and opinions of authors expressed herein do not necessarily state or reflect those of the United States Government or the University of California, and shall not be used for advertising or product endorsement purposes. 


\section{DISCLAIMER}

Portions of this document may be illegible in electronic image products. Images are produced from the best available original document. 


\title{
Magnetic Force Microscopy of Single-Domain Cobalt Dots Patterned Using Interference Lithography
}

\author{
A. Fernandez, P. J. Bedrossian, S. L. Baker, S. P. Vernon, and D. R. Kania
}

Lawrence Livermore National Laboratory, Livermore, CA 94550

\begin{abstract}
We have fabricated arrays of $\mathrm{Co}$ dots having diameters of $100 \mathrm{~nm}$ and $70 \mathrm{~nm}$ using interference lithography. The density of these arrays is $7.2 \times 10^{\prime} / \mathrm{in}^{2}$. Magnetic force microscopy measurements indicate that the $\mathrm{Co}$ dots are single-domain with moments that can be controlled to point either in-plane or out-of-plane. Interference lithography is a process that is easily scaled to large areas and is potentially capable of high throughput. Large, uniform arrays of single-domain structures are potentially useful for high-density, low-noise data storage.
\end{abstract}

\section{INTRODUCTION}

It is anticipated that an alternate form of magnetic media will be required for very high-density data storage. The packing density of thin-film recording media is fundamentally limited by the jaggedness of domain walls which gives rise to noise in the readback signal [1]. In principle, a storage technology based on single magnetic domain particles can overcome this limitation and allow for much higher storage densities [2]-[4]. A single-domain particle can be magnetized in two discrete states with equal but opposite magnetic moments. An array of such particles could be used to record binary information with each particle storing one bit of information.

Recently, several groups have investigated the magnetic properties of small, lithographically defined magnetic structures and considered the possibility of their use for data storage [2]-[4]. New et al. fabricated arrays of $150 \mathrm{~nm}$ by $200 \mathrm{~nm}$ islands patterned from $20 \mathrm{~nm}$ thick Co films [2], [3]. They used electron beam lithography to define the islands and a dry etch process to transfer the pattern. Magnetic force microscopy (MFM) indicates that the islands are single-domain with moments that are in-plane [3]. Using electron beam lithography and electroplating, Krauss et al. fabricated arrays of $50 \mathrm{~nm}$ diameter $\mathrm{Ni}$ pillars with densities as high as $6.5 \times 10^{10} / \mathrm{in}^{2}[4]$. These particles exhibit single-domain behavior with moments that are out-of-plane.

One of the main challenges in developing a storage technology based on single-domain particles is finding a

Manuscript received March 4, 1996.

A. Fernandez, e-mail Fernandez10@llnl.gov, phone 510-424-2904, FAX 510-422-8761. 


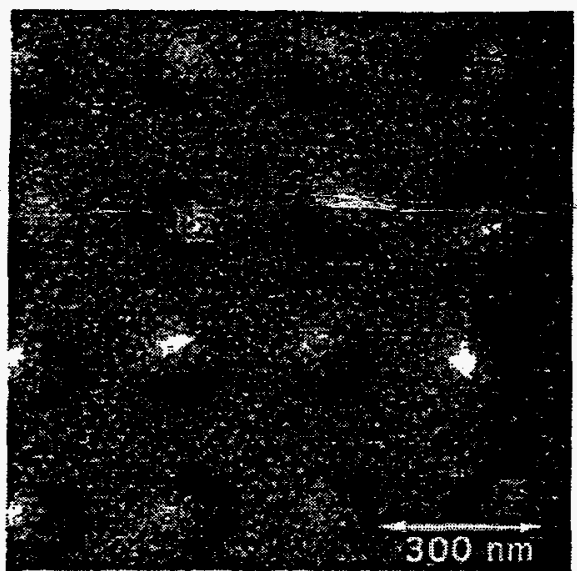

Fig. 1. MFM image of an array of type I Co dots which are $100 \mathrm{~mm}$ in diameter and $40 \mathrm{~nm}$ tall. The dipole signature of these dots indicates the moments are in-plane.

corresponds to a density of $7.2 \times 10^{9} / \mathrm{in}^{2}$. Their diameter is controlled by varying the exposure dose.

Two types of samples are fabricated for this study. In the first type (referred to as type I), the nominal dot diameter is $100 \mathrm{~nm}$ and the Co thickness is $40 \mathrm{~nm}$. In the second type (type II), the nominal dot diameter is reduced to $70 \mathrm{~nm}$ while the Co thickness is increased to $120 \mathrm{~nm}$. A characteristic of this process is that type-II dots are shaped like cones. Cones are formed because the diameter of the holes decrease during deposition due to condensation of Co on the periphery of the holes. Consequently, as the deposition continues, cone shaped dots grow at the bottom of the holes. The tips of the cones are formed as the apertures close. The average height of the type II dots is $100 \mathrm{~nm}$ as measured with an atomic force microscope (AFM). It follows from the above argument that type-I Co dots are shaped like truncated cones with a height of $40 \mathrm{~nm}$.

\section{MAGNETIC FORCE MICROSCOPY}

MFM measurements are performed on a Nanoscope Dimension 5000 AFM. All MFM images are phase images acquired using Digital Instruments' patented LiftMode [11] technique. Fig. 1 shows an MFM image of an array of type I Co dots. The characteristic dipole-like shape of the dots indicates that each dot is uniformly magnetized in a direction parallel to the substrate. This result is consistent with recent studies by New et al. [3] which show that patterned Co particles smaller than $200 \mathrm{~nm}$ are single-domain.

It is clear from Fig. 1 that the in-plane moments of these dots are not preferentially aligned. This is expected since they are circularly symmetric in the plane and therefore do not possess a strong azimuthal shape anisotropy. Dots with an elliptical shape can be fabricated with this process by varying the relative exposure dose for the two orthogonal interference exposures. 

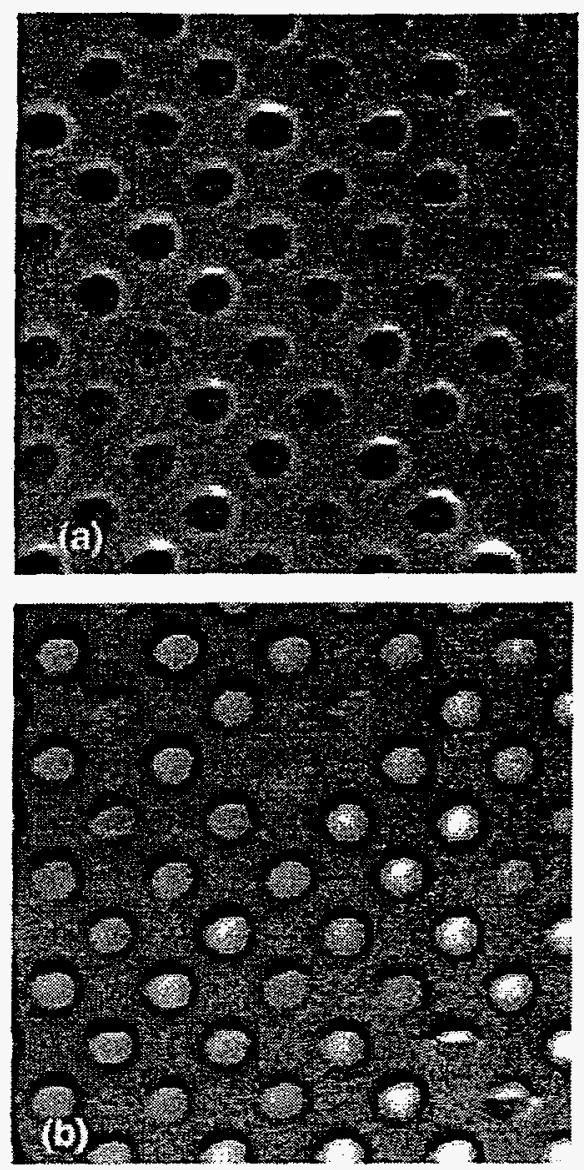

Fig. 4. MFM images of an array of type II Co dots after application of a strong magnetic field along the surface normal in a direction (a) parallel and (b) anti-parallel to the MFM tip moment.

with interference lithography to pattern arrays of small magnetic structures with a wide variety of 3-dimensional shapes. The distinct advantages of using interference lithography over other lithographic techniques are that high-density arrays of nanometer scale structures can be produced over large areas, in a relatively inexpensive way, and with potentially large throughput.

\section{ACKNOWLEDGMENT}

This work was performed under the auspices of the U. S. Department of Energy by the Lawrence Livermore National Laboratory under contract no. W-7405-Eng-48.

\section{REFERENCES}

[1] A. M. Barany and H. N. Bertram, "Transition noise model for longitudinal thin-film media," IEEE Trans. Mag., vol. 23, pp. 1776-1788, March 1987.

[2] R. M. H. New, R. F. W. Pease, and R. L. White, "Physical and magnetic properties of submicron lithographically patterned islands", J. Vac. Sci. Technol. B, vol. 13, pp. 1089-1094, May/June 1995.

[3] R. M. H. New, R. F. W. Pease, and R. L. White, "Effect of magnetocrystalline anisotropy in single-domain polycrystalline cobalt islands," IEEE Trans. Mag., vol. 31, pp. 3805-3807, Nov 1995. 